\title{
Abstracción y regionalismo crítico. Debates arquitectónicos presentes en Aisthesis
}

\author{
Ronald Harris Diez \\ Instituto de Estética, Facultad de Filosofía, Pontificia Universidad Católica de Chile. \\ rharris@uc.cl
}

Frente a la desafiante invitación para reflexionar en torno a los artículos relacionados con el campo de la arquitectura publicados a lo largo de los cincuenta años de historia de la revista Aisthesis, surgió en mí una suerte de inquietud -o, más bien, un prejuicio-. Era muy posible, me pareció, que su número fuera relativamente reducido, teniendo en cuenta que en el medio local existen ediciones gremiales o académicas centradas exclusivamente en ese ámbito. La constatación de la realidad demostró cuán errada estaba mi percepción.

Podría justificar esta primera aprensión, inútilmente, en un acostumbrado reduccionismo que vincula esencialmente a la arquitectura con los volúmenes edificados, dejando de lado otras dimensiones relacionadas con el arte de configurar el espacio, en todo su amplio espectro. Si reparamos en una observación de Roberto Masiero, en la que sostiene los muchos fines y modos en que puede ser entendida la arquitectura, como asimismo los muchos términos que "pueden ayudar a comprender las maneras en que la arquitectura es [concebida] y, por tanto, su esteticidad [...]" (21), resulta posible descubrir que los artículos asociados a esta disciplina presentes en los cincuenta y nueve números de Aisthesis superan el medio centenar.

Siguiendo este lineamiento, quizás sea redundante poner en evidencia que una revista de estudios estéticos convoca una multiplicidad de enfoques desde los más diversos campos de la vida y el arte. De este modo, todos aquellos artículos que a partir de sus correspondientes especificidades invocaron el concepto de espacio y sus problemáticas han sido considerados como parte de este corpus.

Así, los escritos que inauguran este conjunto asoman ya desde el número inicial de la publicación, el cual, de acuerdo con la política habitual de su época, se restringía 
a un tema propuesto: la problemática del teatro en Chile. En esta entrega, se reconocen tres textos vinculados a la arquitectura"; el primero, "Apuntes sobre el teatro en Chile", es de autoría de Alfonso Escudero. Ahí, el autor da cuenta del espectáculo escénico en Chile, desde la dominación española hasta el año de publicación de la revista, 1969. Mención especial merece en el desarrollo de este texto los lugares donde se realizaban dichas representaciones, comenzando por los espacios urbanos -en los que, ante la ausencia de salas de teatro, y con motivo de fiestas religiosas, se llevaban a cabo manifestaciones artísticas- hasta llegar a una exhaustiva revisión de los coliseos que se construyeron a lo largo de la historia de nuestro país. Entre esos incipientes lugares, destaca como el más pintoresco, el cementerio de la Merced, donde Gaspar de Villarroel, Obispo de Santiago entre 1638 y 1652, "refiere haber visto unas comedias" (17). Entre los teatros construidos, llama la atención una mención vinculada a los orígenes de la Pontificia Universidad Católica de Chile:

La manzana Agustinas-Ahumada-Moneda-Bandera, fue, en el último cuarto del siglo pasado, la sede de la Unión Católica, una de cuyas obras fue la Universidad Católica. El último resto que ahí queda, de esa serie de realizaciones católicas, es el nombre de Unión Central en una callecita, y hasta hace poco, el de Teatro Unión Central, que había empezado siendo la sala principal de actos de la primitiva Universidad Católica y hasta ayer fue el Teatro Principal. La inauguración de ese local como teatro comercial data del 2 de mayo de 1895. Fue la primera sala que dio rotativos con películas cortas $(26)^{2}$.

El artículo que cierra este corpus de textos sobre arquitectura apareció en el número 59 de la revista ${ }^{3}$. Fue escrito por Hans Frex y versa sobre un espacio imaginario, la biblioteca de Babel descrita por Borges en el cuento homónimo. En este texto, el académico de la Universidad de Chile medita, bajo el concepto foucaultiano cada día más vigente de heterotopía, sobre la relación exacta entre biblioteca, espacio y conocimiento, aclarando que "según el principio desbaratador del lenguaje, no se

1 Los otros dos artículos fueron de Marta Quintana y Bernardo Trumper. Bajo el título “Adecuación del espacio teatral (las salas de teatro de Santiago)", Quintana realiza un estudio sobre la evolución histórica de esta tipología y sus requerimientos técnicos, acompañado de un interesante dossier de esquemas planimétricos de las principales salas del país en aquel entonces. Por su parte, el texto de Trumper, inscrito en la sección Experiencias, donde connotados realizadores hablan en primera persona de su quehacer profesional, relata lo que él entiende por este arte: "Al igual que la arquitectura, la escenografía crea espacios, pero en el teatro el espacio es dinámico y además es falso, ficticio, ilusorio" (128).

2 Una placa hoy recuerda: "Instituto de Conservación Histórica. En el teatro Unión Central, situado en este lugar, en la tarde del 25 de agosto de 1896 se efectuó, la primera proyección del cinematógrafo en Chile que comprendió una breve vista titulada El mar, de los hermanos Lumiere. Ilustre Municipalidad de Santiago, Exhibidores y Cineastas de Chile, 1996."

3 Otros dos artículos de este número tocan también, aunque tangencialmente, el asunto arquitectónico: por un lado, un texto de Pierre Chateau sobre el Museo de Arte Contemporáneo de la Universidad de Chile (MAC), que trata más bien sobre temas vinculados a criterios curatoriales, sin llegar a hacerse cargo del edificio en sí mismo; por otro lado, un escrito de Antonio Becerra y Nayra Pérez en torno al tratamientos de los 'espacios narrativos', desarrollados en dos novelas noir del autor canario Alexis Ravelo, género literario que, por lo demás, nace en conjunto con la ciudad moderna, como recuerda Mari Paz Balibrea, citada por los autores: "el crimen no es una aberración temporal sino un rasgo definitorio del mundo contemporáneo, más específicamente urbano” (76). 
puede incluir a la biblioteca dentro de la heterotopía, pero sí el lenguaje del cuento de Borges, donde no se configura un espacio de acumulación, organización y localización del saber, sino un espacio heterotópico de su dispersión” (39).

De este modo, entre el espacio escénico y las construcciones imaginarias, se despliega un amplio espectro de textos que, explícitamente o de manera oblicua, extendiéndose por casi todos los números de la revista, abordan problemáticas del espacio y la arquitectura. Tropezando con las restricciones que comporta un ensayo de estas características, valga como un desvaído atenuante mencionar los términos que más se reiteran en los títulos de los artículos, buscando obtener con ello una radiografía sinóptica de las problemáticas arquitectónicas que, desde la estética, se han abordado en Aisthesis: ciudad, espacio público, paisaje, territorio, lugar y trayecto.

Nuevamente, vanos escrúpulos podrían hacernos pensar que estas entradas nos remiten a debates arquitectónicos meramente contingentes. Sin embargo, estos términos, que se repiten sincopadamente a lo largo de los cincuenta años de la revista, semejan constituirse como una evidencia concreta de las discusiones arquitectónicoexistenciales, críticamente examinadas por la postmodernidad

Sin poder reseñar este vasto acopio de escritos y evitando ejercer de juez a la hora de seleccionar aquellos que hoy nos puedan parecer más relevantes, es que creo conveniente que fijemos nuestra atención en el único número monográfico de Aisthesis centrado en la arquitectura ${ }^{4}$. Como reflejo de la importancia que revestía esta temática para el entonces Centro de Investigaciones Estéticas, ya el número 4 de la publicación fue destinado a "La arquitectura y sus problemas en Chile". En esa entrega, a modo de un symposium, según establece Raimundo Kupareo en la presentación, se convocó a estetas, arquitectos e historiadores de la Arquitectura -indicado con mayúscula-, para dialogar sobre el sentido de la disciplina y sus proyecciones en nuestro país. La pléyade de autoridades en la materia, algunos todavía con mucha vigencia en el medio, es relevante. Visto desde la perspectiva que da el tiempo, sorprende un texto de Vittorio di Girolamo, donde en primera persona relata sus experiencias y diálogos con el afamado arquitecto Oscar Niemeyer; asimismo, resulta interesante una entrevista de Carlos González al desatacado vitralista y pintor austríaco radicado en Lima, Adolfo Winternitz, quien por aquellos años había realizado las vidrieras de dos connotadas obras de la arquitectura moderna nacional: el templo votivo de Maipú y la capilla del Colegio del Verbo Divino.

El año de publicación de este número, 1969, es un dato relevante como primera aproximación para valorar los artículos allí presentes. Por una parte, el número de revistas vinculadas al ámbito de la arquitectura en nuestro país siempre había sido

4 Otros dos números de la revista fueron parcialmente consagrados a la arquitectura. Aisthesis 23, de 1990, reunió una serie de textos que, a propósito de los 25 años de Aisthesis, abordaban el devenir del arte en Chile en los últimos 25 años, desde diversas disciplinas.

En Aisthesis 41, de julio de 2007, la revista decidió incorporar una sección dossier, que emulara la antigua tradición de las monografías. Ese número reunió cuatro artículos en torno al tema de "Estética y ciudad Latinoamericana". 
exiguo $^{5}$, escasez acrecentada por el hecho de que entre 1950 y 1965, prácticamente no se editaron revistas periódicas (Eliash y Moreno 174). Para finales de la década del sesenta, sin embargo, habían tres en circulación: Arquitectura, Urbanismo, Construcción $y$ Arte (AUCA); la publicación oficial del Colegio de Arquitectos (C/A); y la Revista de la Construcción. Con diferente periodicidad, estas revistas editaron en conjunto dieciocho números ${ }^{6}$, todo un portento para el contexto enunciado. Dentro de este panorama, la nueva tribuna que ofrecía Aisthesis era igualmente valiosa, ya que debido a su perfil y convocatoria, ampliaba el espectro de perspectivas y, sobretodo, de lectores, pues las otras publicaciones se centraban mayoritariamente en profesionales, académicos y estudiantes del rubro, rol que objetivamente, por lo demás, aún cumple nuestra revista.

Por otro lado, 1969 es un año relevante en lo que respecta a la arquitectura moderna. Según concuerda la historiografía nacional, el fin de los años sesenta marca el agotamiento y fin de las propuestas asociados con este discurso, que habiéndose gestado en Europa en los inicios del siglo pasado, se había internacionalizado a partir de la década de 1930. Por ello, Aisthesis 4 se revela en retrospectiva como una pieza importante para comprender las crisis de este proceso, y de paso poder atisbar cómo algunas de las críticas que manifiestan sus textos germinarán hasta convertirse en un contra-discurso, cuyos frutos se concretaran en obras arquitectónicas a partir de finales de la década del ochenta.

Los tópicos que transversalmente más se reiteran en los artículos y que traspasan los límites temáticos impuestos para ese número de la revista son cuatro: Teorías, Arquitectura y Urbanística en Chile, Experiencias y Documentos. Todos estos guardan relación con problemáticas vinculadas al lenguaje arquitectónico, particularmente en lo que respecta a la abstracción de las formas. En el entendido actual, tal como establece el investigador Max Aguirre, la conversión hacia la arquitectura moderna consistió en pensar el proyecto y la obra bajo un régimen de racionalidad científica, la cual encontró su realidad arquitectónica formal en el predominio de la geometría (28).

El abandono de la arquitectura concebida como una cuestión de estilo -en claro correlato con un sistema de significación social-, fue un proceso paulatino, e increíblemente, para la fecha de publicación de la revista, la abstracción alcanzada por la arquitectura era aún un problema en discordia. Este hecho se manifiesta en las variadas posturas que adoptan los autores; mientras algunos afirman que la arquitectura del pasado nunca había abandonado el lenguaje de las formas figurativas, acusando, por lo tanto, a la abstracción moderna de prosaica e iconoclasta (Michelis 16), otros destacan este aspecto como algo propio a la naturaleza de la arquitectura.

5 Ver: Aguirre, Max. La Arquitectura moderna en Chile (1907-1942): Revistas de Arquitectura y estrategia gremial. Santiago de Chile: Universitaria, 2012; y Mondragón, Hugo. El discurso de la Arquitectura Moderna. Chile 1930 1950. Una construcción desde las publicaciones periódicas. Tesis Doctoral. Universidad Católica de Chile, 2010.

6 En 1969, la revista $A U C A$, de carácter cuatrimestral para la época, lanzó los números 14 al 16, mientas que C/A, con la misma periodicidad, editó los números 4 al 6 -correspondientes a los meses de enero, julio/agosto y octubre/ noviembre-. Por su parte, la Revista de la Construcción, de tiraje mensual, publicó los número del 80 al 91. 
De este modo, Raimundo Kupareo afirma, desde el campo de la filosofía, que la abstracción es algo intrínseco al quehacer de la arquitectura, constituyéndose, por lo demás, como la mayor de sus fortalezas respecto de las otras artes. El autor realiza esta afirmación entendiendo que la arquitectura no imita simplemente a la naturaleza, sino que crea un nuevo orden, no en contraposición, sino que en paralelo a ella. Por último, Kupareo concluye que:

La Arquitectura ocupa -(por favor, ¡que no se ofendan los demás artistas!)- el primer puesto en la escala artística, no cronológicamente o por su valor intrínseco (que es igual en todas las clases de Arte), sino por su mayor "abstracción”. Ella puede prescindir del color, sonido, palabra, etc. Su juego es "abstracto"; juego de las formas espaciales. La Arquitectura no es la hija de la geometría ("filie de la géometrie", como dijo Viollet-le-Duc), sino su "hermana"; la geometría trata de la extensión abstracta, en el sentido propio, mientras que la Arquitectura "concretiza" esta extensión al servicio de la "idea" (sentimiento intuido). ¡Nemo architectus nisi geometres! Por tal razón, ella es la primera. El "arqué" (31).

Al repudiar los referentes históricos, la arquitectura moderna dejaba de lado también el "sentido de belleza como un objetivo del resultado formal" (Aguirre 28). Ahora, la apariencia del edificio estaba determinada por otros principios, vinculados mayoritariamente a las decisiones que tomaba el proyectista, en relación con el empleo de nuevos materiales constructivos y de las tecnologías asociadas a su uso ${ }^{7}$. En resonancia con esta problemática, Milan Ivelic, en un texto donde discute sobre los modos y los medios de expresión arquitectónicos -la especificidad de cada lenguaje artístico era una discusión fuertemente arraigada en el discurso estético de la época, como parecen revelarlo los artículos de la revista-, establece, parafraseando a Sven Hesselgren, que: Es fundamental que el arquitecto conozca muy bien los medios con los cuales el lenguaje arquitectónico se expresa para la creación de formas espaciales concretas. Uno de esos medios, ya lo dijimos, es la construcción, que a cada momento está presentando nuevas posibilidades de expresión; de igual manera ocurre con los materiales que, naturalmente, no pueden separarse de la construcción, ya que toda construcción supone siempre la construcción con un material. Sus atributos característicos están relacionados con su estructura física y, por lo tanto, sólo si el arquitecto conoce realmente sus atributos físicos y todos los recursos y posibilidades que existen para dominarlos, será capaz de aprovecharlos para que contribuyan en la creación de formas espaciales (45-46).

7 "La Arquitectura moderna se identifica con el cambio radical en la manera de concebir el proyecto a partir del siglo xx. Este fenómeno comenzó a surgir en el mundo durante el siglo xIx, principalmente con la incorporación de criterios de decisión fundados en nuevos materiales, en las tecnologías asociadas a su aplicación, en la producción industrial y en la estandarización de la construcción que hicieron abandonar los estilos, los ornamentos historicistas y la belleza, hasta entonces, base tradicional de la arquitectura. Estos aspectos incidieron al interior de la disciplina e indujeron nuevos principios con los que pensar el proyecto" (Aguirre 22). 
Si bien el texto de Ivelic hablaba del lenguaje arquitectónico desde una perspectiva atemporal, otras muchas propuestas presentes en la revista criticaban esta postura llevada al extremo por la arquitectura moderna, tal cual lo expresaba de forma bastante coloquial -tono habitual para la época, hoy considerado políticamente incorrecto en el ámbito de las publicaciones científicas-, Raúl de Ramón:

\begin{abstract}
Todo tiene una razón de ser y se ha llegado por ese camino a terribles arideces, ya que lo decorativo no parece urgente, y la complacencia espiritual y estética es postergada por el imperativo de los materiales. Es que los chilenos somos el colmo de lo exagerado - a la española, mal que les pese a muchos-. Todo tiene que extremarse y la prudencia de "ni muy adentro que te quemes, ni muy afuera que te hieles" parece una cobardía acomodaticia, burguesa y cincuentona. La habitación es una máquina de vivir, se ha dicho. Pero maldita la gracia que hace vivir dentro de una máquina, perfecta, pulida e imperativa (55).
\end{abstract}

Más allá de su carácter pintoresco, el juicio de este autor encarna una crítica que subyace en los artículos de la revista, en la cual se acusaba a la arquitectura moderna de carecer de sentido de lugar y de identidad propia. Si bien el hacer una arquitectura con impronta propia había sido una preocupación latente a todo lo largo del siglo $\mathrm{xx}$, la incapacidad de la arquitectura moderna de configurar propuestas en torno a estas problemáticas, más allá de algunos casos individuales, fue uno de los flancos por donde más se le fustigo a nivel mundial.

En este sentido, la preocupación a este respecto, explícita en los textos de muchos de los articulistas, parece refrendar la tesis que por aquellos años fraguaría Kenneth Frampton, en relación con lo que él denominaría "regionalismo crítico"8. Concebida como una categoría critica, más que como un estilo, buscaba caracterizar a aquellas propuestas arquitectónicas donde se enfatizaba la relación entre lo construido y el territorio, es decir, "cultivar una cultura contemporánea orientada hacia el lugar" (332). De esta manera, se hacía un reconocimiento respecto de las singularidades del emplazamiento, en cuanto a topografía, luz y condiciones climáticas.

Claramente se reconocen estas inquietudes en el texto de Oscar Zacarrelli, que si bien está orientado a reconocer ciertos aspectos formales característicos de la arquitectura moderna -enfoque que sería repudiado por algunos críticos actuales, pero que se condice con ciertas perspectivas de la época que aún entendían estas propuestas como un estilo-, buscaba identificar en las obras de algunos arquitectos chilenos, la huella de una identidad propia que condensara en sus formas las propuestas de la arquitectura moderna internacional, con el potencial crítico y artístico del país:

Creemos seriamente que hay indicios de una arquitectura "nacional", que sin desentenderse totalmente de ciertas coincidencias mundiales (sería utópico que

8 Ver: Frampton, Kenneth. Historia critica de la arquitectura moderna. Barcelona: Gustavo Gili, 2000. Esta tesis es desarrollada en el capítulo "El regionalismo crítico: arquitectura moderna e identidad cultural", páginas 318 a 332. 
sucediese de otra manera), prometen una definición de nuestras formas que, lejos de evocar sentimentalismos históricos, se apoye en una respuesta veraz y viril a nuestra gente, a nuestras costumbres, a nuestros climas, a nuestros contornos naturales, a nuestro suelo montañoso y sísmico, a nuestra vegetación y a nuestro largo y pintoresco océano.

La base racional del proyecto moderno, y del cual el regionalismo crítico no pretendía renegar, buscaba evitar cualquier "simulación sentimental de la arquitectura vernácula" (332), tal cual se evidenciaba en el texto de Zacarrelli. No así otros, como el ya citado artículo del arquitecto Raúl de Ramón, que impregnado de una añoranza del pasado, hace un repaso de los tipos vernáculos de vivienda, tanto urbanas como rurales, del valle central de Chile. De cierta manera, esta mirada nostálgica por el pasado distancia este texto de las propuestas formuladas por Frampton, para acercarlo a una sensibilidad relacionada con lo que en los años venideros derivará en lo que se conoce como arquitectura postmoderna.

Este artículo tenía por claro fin instarnos a concebir una vivienda moderna que se nutriera de los valores que evidencian estas construcciones, a saber, una adecuada relación con su entorno y su clima. "Busquemos el espacio chileno", invoca De Ramón en uno de sus acápites. Para él, estos espacios serían, por ejemplo, los patios, en torno a los cuales se organizaban las estancias que conformaban la tradicional casa del valle central, argumentando que sus orígenes se remontaban a los modelos de viviendas que trajeron los "hidalgos españoles" (57).

Sin referirse directamente a ello, su escrito finaliza con cuatro fotografías que ilustran una casa diseñada por él. Sin referencias que identifiquen la residencia, las imágenes aparecen agrupadas bajo el rótulo "Un ejemplo de aplicación de la arquitectura tradicional". Es evidente que su autor buscaba proponerla como un modelo de casa moderna que rescataba los valores de las viviendas vernáculas analizadas. Más discutible es el hecho de que más allá de la presencia de muros que semejan pircas y objetos que evocan la vida campestre de nuestro país, la casa, tanto morfológica como espacialmente, más bien nos remite a la arquitectura tradicional japonesa. Esto se hace particularmente evidente al observar, por ejemplo, los pequeños pilotis que elevan la casa, la grava blanca que cubre el patio central y los muros y ventanales que, modulados ortogonalmente en grandes paños, remiten a los paneles movibles -llamados shōji- que dividen los recintos de las casas japonesas tradicionales. Quizás la configuración espacial de las estancias principales sea lo más evidente, pues se trata de un amplio y único espacio que remata visualmente en un jardín interior que evoca los jardines orientales.

Para ser justos con su creador, debemos reconocer que esta mirada puede ser un privilegio que nos otorga el distanciamiento temporal, ya que entendemos que muchos de los principios de la arquitectura tradicional japonesa subyacían en las propuestas del movimiento moderno y estaban tan asimilados, que se hacía difícil distinguirlos. 
Concluyendo con esta revisión, es pertinente volver a aclarar que las temáticas arquitectónicas abordadas en la revista Aisthesis superan con mucho las restricciones de extensión impuestas para este ensayo. A esto debemos agregar que la selección de los tópicos tratados, sin lugar a dudas, está sesgada por mi vinculación con áreas de estudio ligadas a la historia de la arquitectura. Es evidente que para poder subsanar estas limitantes, solo me es posible extenderles una invitación a consultar los más de cincuenta artículos vinculados a problemáticas arquitectónicas que están presentes en nuestros números.

Cabe señalar, por último, que temas como la arquitectura sustentable y el paisajismo están aún algo ausentes en nuestras páginas, y si bien son abordados en los cursos de nuestro Magíster en Estéticas Americanas, hacemos extensible también la invitación a publicar en Aisthesis sobre estas y otras problemáticas de la arquitectura actual.

\section{Referencias}

Aguirre, Max. La arquitectura moderna en Chile: El cambio de la arquitectura en la primera mitad del siglo XX. El rol de la organización gremial de los arquitectos (1907-1942) y el papel de las revistas de arquitectura (1913-1941). Tesis Doctoral. Universidad Politécnica de Madrid, 2004. Web.

Becerra, Antonio y Nayra Pérez. "Espacios y memoria del mal: en torno a La iniquidad de Alexis Ravelo". Aisthesis 59 (2016): 75-90. Impreso.

De Ramón, Raúl. “Arquitectura tradicional del 'Chile Viejo"'. Aisthesis 1 (1966): 5376. Impreso.

Escudero, Alfonso. “Apuntes sobre el teatro en Chile”. Aisthesis 1 (1966): 17-61. Impreso.

Eliash, Humberto y Manuel Moreno. Arquitectura y modernidad en Chile: una realidad múltiple 1925-1965. Santiago de Chile: Ediciones ARQ, 1989. Impreso.

Frex, Hans. "El espacio bibliotecario del saber. De Foucault a Borges". Aisthesis 59 (2016): 23-40. Impreso.

Ivelic, Milan. “El lenguaje arquitectónico”. Aisthesis 4 (1969): 39-49. Impreso.

Masiero, Roberto. Estética de la arquitectura. Madrid: A. Machado Libros, 2003. Impreso.

Michelis, P. A. "El lenguaje de las imágenes en la arquitectura". Aisthesis 4 (1969): 11-32. Impreso.

Trumper, Bernardo. “Experiencias de un Escenógrafo”. Aisthesis 1 (1966): 125-132. Impreso.

Zacarrelli, Oscar. "Las nuevas formas de la Arquitectura en Chile”. Aisthesis 1 (1966): 77-92. Impreso 